\title{
Exploring the relationship between campus leadership development and undergraduate student motivation to lead among a Malaysian sample
}

\begin{abstract}
Despite the number of studies investigating the perceived effectiveness of campus-based leadership development programming among undergraduates, most have focused on programme outcomes and few have investigated the role of the campus environment in enhancing students' motivation to lead, particularly in non-Western contexts. To address these gaps, the current study investigated the relationship between perceived campus support for leadership development and both campus leadership involvement and undergraduate students' motivation to lead. Data were gathered from 368 undergraduates from Malaysian public institutions of higher learning. An instrument to measure perceived campus support for leadership was developed through extensive review of the related literature. Exploratory multiple stepwise regression results showed that extent of involvement in leadership on campus, perceived quality of leadership training, perceived leadership opportunities on campus, quality of staff support for leadership on campus and programme of study accounted for a significant amount of the variance in predicting motivation to lead. The results lend initial support for the need for more experiential learning opportunities, high-quality training and greater staff-student engagement to enhance student motivation to lead. The findings draw particular attention to current university leadership training approaches that focus solely on transfer of skills and knowledge, such as those still employed in many universities. Implications for improving undergraduate student motivation to lead are discussed.
\end{abstract}

Keyword: Leadership; Motivation; Undergraduates; Campus; Asia; Malaysia 